\title{
A relação entre o investigador e sujeito-participante na investigação biográfica em educação
}

A investigação biográfica em educação fundamenta-se no pressuposto que a biografização é um processo essencial, através do qual o sujeito dá forma e atribui sentido à sua existência, interpreta as suas experiências e faz da sua vida uma história, o que lhe permite um fortalecimento identitário. A biografização tem um papel fundamental na (re)elaboração da experiência, na construção de si, na formação do sujeito e na promoção do poder de agir. Estes elementos evidenciam a centralidade da atividade biográfica na vida das pessoas, o que justifica a importância da investigação biográfica, porquanto, esta permite compreender e potenciar a formação dos indivíduos e a construção identitária, processos em constante transformação, numa sociedade em movimento, na qual emergem novas problemáticas.

A especificidade de modalidades e de finalidades das entrevistas na investigação biográfica, inscritas num processo dialógico, incitam à reflexão sobre a relação induzida entre o investigador e os sujeitos-participantes. Os textos apresentados neste número temático procuram analisar e problematizar esta relação, a partir de três dimensões interdependentes:

1) a dimensão ética e deontológica que, implicando o sujeito na investigação, exige a construção de uma relação de informação, de negociação, de empatia, de confiança, de honestidade, de respeito, de reconhecimento e de valorização do outro na sua singularidade;

2) a dimensão heterobiográfica, que inscreve as trocas numa interação social, por um lado, entre o sujeito-participante "em posição de inquiridor de si próprio" e, por outro lado, "o investigador que visa criar condições e compreender o trabalho realizado pelo sujeito-participante sobre si próprio" (Delory-Momberger, 2014, p. 79). 0 sujeito-participante e o investigador questionam-se reciprocamente, o que faz da investigação um espaço-tempo construído na relação e na co-construção;

3) a dimensão de envolvimento social, na medida em que as narrativas produzidas nas entrevistas estão estreitamente ligadas à ação dos sujeitos, à qual dão forma e sentido, realizando a sua subjetivação. Neste sentido, as entrevistas apresentam um potencial transformador e emancipador dos sujeitos-participantes, mas também do próprio investigador. A análise e a problematização destas três dimensões contribuem para o aprofundamento da reflexão metodológica levada a cabo pelos investigadores inscritos no campo
Carmen Cavaco Anne Dizerbo (Organizadoras) 
da investigação biográfica em educação, assim como, para pôr em evidência as potencialidades deste tipo de investigação, em termos de desenvolvimento do poder de agir dos sujeitos implicados, nomeadamente, a sua capacidade para participar em mudanças sociais.

O número temático é constituído por seis textos decorrentes de investigações biográficas realizadas em Portugal, França e Brasil. Os textos incidem em investigações com crianças, jovens e adultos, a partir de objetos de estudo distintos. As investigações centraram-se no estudo da experiência dos sujeitos-participantes, nomeadamente, a experiência escolar de alunos integrados numa escola de intervenção prioritária; as trajetórias biográficas de jovens, com experiência de abandono escolar, em situação de reingresso escolar; a experiência de vida de jovens adultos universitários, a experiência de vida e o processo de formação de adultos analfabetos; a experiência profissional de educadores de adultos e de profissionais de saúde. Os textos visam contribuir para a reflexão sobre a dimensão relacional da investigação biográfica em educação, as questões éticas e deontológicas que lhe estão inerentes, assim como, a compreensão e a promoção do poder de agir dos sujeitos-participantes.

\section{REFERÊNCIAS BIBLIOGRÁFICAS}

Delory-Momberger, C. (2014). De la Recherche Biographique en Éducation. Fondements, méthodes, pratiques. Téraèdre. 


\section{Le rapport aux personnes-sujets des chercheurs inscrits dans le champ de la recherche biographique en education}

La recherche biographique en éducation part du présupposé que la biographisation est un processus essentiel par lequel un individu donne forme et sens à son existence, interprète ses expériences et fait de sa vie une histoire qui lui donne une cohésion identitaire. Ce processus a donc un rôle fondamental dans l'élaboration de l'expérience, dans la construction de soi, dans sa formation, et dans la construction de son pouvoir d'agir. Ces éléments mettent en évidence la place centrale de l'activité biographique dans vie des personnes, d'où l'importance de la recherche biographique qui permet d'appréhender les processus de construction identitaire et de formation d'individus en constante transformation dans une société en mouvement qui fait émerger de nouvelles problématiques. La spécificité des modalités et des finalités des entretiens dans la recherche biographique, qui s'inscrivent dans un processus dialogique, invite à penser la relation qu'il induit entre les chercheurs et les personnes-sujets. Dans ce dossier thématique nous essaierons d'analyser et de problématiser cette relation en l'inscrivant dans trois dimensions interdépendantes :

1) la dimension éthique et déontologique qui, impliquant le sujet dans la recherche, exige la construction d'une relation d'information et de négociation, d'empathie, de confiance, d'honnêteté, de respect, de reconnaissance et de valorisation de l'autre dans sa singularité;

2) la dimension hétérobiographique, qui inscrit les échanges dans une interaction sociale entre, d'un côté, la personne-sujet « en position d'enquêteur de lui-même » et, de l'autre côté, « le chercheur dont l'objet propre est de créer les conditions et de comprendre le travail de l'enquêté sur luimême » (Delory-Momberger, 2014, p. 79). La personne-sujet et le chercheur se questionnent réciproquement, ce qui fait de la recherche un espace-temps de formation construit dans la relation et dans la co-construction ;

3) la dimension d'engagement social, dans la mesure où les récits produits pendant les entretiens sont très étroitement liés à l'action des sujets, à laquelle ils donnent forme et sens, et permettent en même temps leur subjectivation. En ce sens, les entretiens constituent un potentiel transformateur et émancipateur des personnes-sujets, mais aussi du chercheur. L'analyse et la problématisation de ces trois dimensions viendra contribuer à l'approfondissement de la réflexion méthodologique menée par les chercheurs s'inscrivant dans le champ de la recherche biographique et mettre en évidence ses potentialités en termes de développement du pouvoir d'agir des sujets et de leur capacité à engager des changements sociaux.
Carmen Cavaco Anne Dizerbo (Organisateurs) 
Le numéro thématique est composé par six textes rendant compte de recherches biographiques réalisées au Portugal, en France et au Brésil. Les textes concernent des recherches portant sur des objets d'étude différente, auprès d'enfants, de jeunes ou d'adultes. Ces recherches sont centrées sur l'expérience des sujets-participants, notamment, l'expérience scolaire d'élèves inscrits dans un collège de zone d'éducation prioritaire ; les trajectoires biographiques de jeunes, anciens décrocheurs en situation de raccrochage scolaire ; l'expérience de vie des jeunes et adultes à l'université; l'expérience de vie et le processus de formation d'adultes analphabètes, l'expérience professionnelle de formateurs des adultes et de professionnels de santé. Les textes contribuent à une réflexion sur la dimension relationnelle de la recherche biographique en éducation, les enjeux éthiques et déontologiques qui lui sont inhérents, ainsi que la compréhension et la promotion du pouvoir d'agir des sujets participants.

\section{RÉFÉRENCES BIBLIOGRAPHIQUES}

Delory-Momberger, C. (2014). De la Recherche Biographique en Éducation. Fondements, méthodes, pratiques. Téraèdre. 